\title{
Mechanical and structural evaluation of friction stir welded 6061 aluminium alloy lap joints at different welding speeds
}

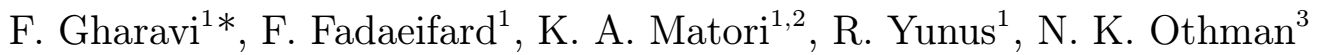 \\ ${ }^{1}$ Materials Synthesis and Characterization Laboratory, Institute of Advanced Technology, Universiti Putra Malaysia, \\ 43400 UPM Serdang, Selangor, Malaysia \\ ${ }^{2}$ Department of Physics, Faculty of Science, Universiti Putra Malaysia, 43400 UPM Serdang, Selangor, Malaysia \\ ${ }^{3}$ Schools of Applied Physics, Faculty of Science and Technology, Universiti Kebangsaan Malaysia, \\ 43600 UKM Bangi, Selangor, Malaysia
}

Received 7 May 2015, received in revised form 21 November 2015, accepted 8 December 2015

\begin{abstract}
Lap joints of 6061-T6 aluminium alloy were produced by friction stir welding, and the influence of welding speed on their weld quality was investigated in terms of welding defects, micro- and macrostructures, hardness distribution, and tensile properties as well as effective plate thickness (EPT) by applying the welding speed in the range $20-60 \mathrm{~mm} \mathrm{~min}^{-1}$ at constant rotation speed of $1000 \mathrm{rpm}$. The results showed that although tensile shear strength, joint efficiency, and microhardness of the weld nugget zone (WNZ) rather than the heat affected zone (HAZ), and the EPT increased with an increase in welding speed, the average grain size in the WNZ rather than the HAZ decreased. Due to increasing welding speed, the hooking and thinning defects were gradually restricted from the WNZ to the WNZ/TMAZ interface. The fracture mode within the highest tensile shear strength joints was denoted as plate separation along the hook throughout the stir zone.
\end{abstract}

K e y w o r d s: friction stir welding, 6061 aluminium alloy, mechanical properties, microstructure, welding speed

\section{Introduction}

Friction stir welding (FSW) process is an emerging "green" solid-state method in which joining of metal plates is done based on a thermo-mechanical action used by a non-consumable welding tool onto metal plates [1]. FSW has increasingly been applied particularly in situations where solidification cracking, liquation cracking, and microporosity formation need to be avoided [2]. Friction stir welding can be especially advantageous for $\mathrm{Al}$ alloys as the process imparts a low heat input and has the flexibility of joining cast, extruded, and rolled materials without requiring complicated surface preparation or shielding gas protection $[3,4]$. FSW can also assemble different joining configurations such as lap, butt, and

T-joints, of which the lap joints are widely applied in automotive, aeronautic, and shipbuilding industries to replace self-pierce rivet joining as well as to produce firm panels and beam assemblies where the joining of the stringers and frames to the main body of a structure is required $[5,6]$. In FSLW, the tool was made to penetrate into the lower plate to a certain depth. For this reason, the original plate interface on either side of the weld slightly bends upwards or downwards (due to tool geometry and welding parameters). This means that the original plate interface provides somewhere to stay the tool penetration and its translation, called the hooking effect [7]. This wavy flaw in advancing side is called hooking while on the retreating side, it is called thinning. The existence of hooking and thinning decreases the effective plate thickness (EPT) in one of the plates (top or bottom), and thereby reduces the load-carrying capacity when a friction stir lap weld is loaded. Although the mechanical characteristic of friction stirs processed material in the weld zone has a determinative effect on the shear strength of a lap joint, the effective plate thickness (EPT) of

*Corresponding author: tel.: +006 01 76350637; fax: +006 03 89454454; e-mail address: drfgharavi@gmail.com 
Table 1. Nominal chemical composition of materials used in FSLW experiments (wt.\%)

\begin{tabular}{lcccccccccc}
\hline Alloy & $\mathrm{Al}$ & $\mathrm{Si}$ & $\mathrm{Fe}$ & $\mathrm{Cu}$ & $\mathrm{Mn}$ & $\mathrm{Mg}$ & $\mathrm{Cr}$ & $\mathrm{Ti}$ & $\mathrm{Zn}$ & 0.02 \\
\hline Al6061-T6 & 97.45 & 0.66 & 0.3 & 0.27 & 0.07 & 1.0 & 0.18 & 0.05 & 0.02 \\
\hline
\end{tabular}

Ta ble 2. Mechanical properties of the 6061-T6 aluminium alloy used in this work

\begin{tabular}{cccc}
\hline Yield strength $(\mathrm{MPa})$ & Ultimate strength $(\mathrm{MPa})$ & Elongation $(\%)$ & Hardness, HV \\
\hline 280 & 310 & 15 & 105 \\
\hline
\end{tabular}

Table 3. Summary of material types and workpiece dimensions used in FSLW experimental series

\begin{tabular}{cccc}
\hline Materials & Upper plate thickness $(\mathrm{mm})$ & Bottom plate thickness $(\mathrm{mm})$ & Plate dimensions $\left(\mathrm{mm}^{2}\right)$ \\
\hline Al 6061-T6 to Al 6061-T6 & 5 & 5 & $220 \times 140$ \\
\hline
\end{tabular}

the top or bottom plates that increases by suppressing the hooking and thinning could be more effective to rise the joint strength $[8,9]$.

The influence of some important welding parameters such as heat input (HI), welding speed $(v)$, rotational speed $(\omega)$, and weld pitch $(\omega / v)$ on weld features such as tensile properties and fracture locations has been investigated by some researchers [10 12 . It is important to note that it is difficult to estimate the thermal input and mechanical properties due to the changing of both rotation speed and welding speed quantitatively. The thermal input and mechanical properties are parameters dependent on the rotation speed and welding speed [13-19]. In FSLW, mechanical deformation, heat caused by friction, and the post-weld cooling rate will cause to occur a great modification of the original alloy microstructures. Accordingly, the certain regions will create within the weldments. Each of these regions is microstructurally different than other regions. Any region that has experienced the highest temperature and plastic deformation shows the different microstructure from another region that has experienced less heat and deformation. It should be noted that the heat required for softening the material is generated by a combination of the profiled shoulder and the pin during the welding process. Accordingly, the temperature of heat generated raises to the range of $0.8-0.9$ from the melting point of the joint material. Thus, the maximum temperature in the weld region is revealed within the WNZ. This temperature creates by the severe deformation of the material under the tool welding, so that the transition of the temperature will gradually decrease from the WNZ to the parent alloy. The generation of heterogeneous microstructure within the weld region as opposed to the parent alloy can be related to the difference in the thermal gradient between the weld region and the parent alloy. The variation in the microstructure after FSLW is an important parameter that has a significant impact on the mechanical properties of welded joints.

As a matter of fact, some restricted effects of friction stir welding parameters such as welding speed, rotational speed on the mechanical properties and fracture locations of the friction stir lap welded $\mathrm{Al}$ alloys, have been studied by some authors [20-22]. Therefore, this work reports on the study of the FSLW of 6061-T6 aluminium alloy, with the emphasis placed on the weld integrity, weld microand macrostructures, hardness distribution, tensile shear strength, and fracture behaviour of AA6061-T6 Al alloy lap joints welded at different welding speeds as well as the effect of EPT (effective plate thickness) on shear strength of welded lap joints.

\section{Experimental method}

\subsection{Material selection}

The investigated alloy is a member of AA6XXX heat treatable aluminium alloys. AA 6061 is one of the most popular members of this group which includes $\mathrm{Mg}-\mathrm{Si}-\mathrm{Cu}$ alloying elements. The parent alloy was a wrought 6061-T6 aluminium alloy plate. Tables 1 and 2 show the nominal composition as well as mechanical properties of the alloy used in this study.

\subsection{Welding preparation}

Before proceeding with welding process, it is vital to prepare the plates for welding. Summary of materials and workpiece dimensions used in each series is given in Table 3 . 
Ta ble 4. Process parameters for fabricating FSLW joints at constant rotation speed

\begin{tabular}{lccc}
\hline Series & No. & Welding speed $\left(\mathrm{mm} \mathrm{min}^{-1}\right)$ & Rotation speed $(\mathrm{rpm})$ \\
\hline Al 6061-T6 & 1 & 20 & 1000 \\
& 2 & 40 & 1000 \\
& 3 & 50 & 1000 \\
& 4 & 60 & 1000 \\
\hline
\end{tabular}

The dimensions were selected according to the AWS standard D17.3 [23]. Plates were cut using a handheld Skilsaw radial saw with a metal cutting blade. It should be emphasized that the longitudinal direction of the plates was parallel to the plate rolling direction. The plates were then wiped clean with a soap solution to remove metal shavings or dirt. The joining process was carried out in a Computer Numerical Control (CNC) machine. To enhance weld consolidation, the tool was tilted at 3 degrees forward from the vertical in the direction behind the tool during welding. Additionally, joints were produced with a single pass welding procedure. The tool used in this research was CNC machined from H13 tool steel bar. After final machining, a quench-temper heat treatment was conducted based on metals handbook [24] with some changes that obtain higher mechanical properties and hardness for these kinds of the alloy. The hardness of welding tool became $50 \mathrm{HRC}$ after heat treatment. The shape of the shoulder and the pin was cylindrical, and the head of the pin was also selected as sub-conical. Figure 1 displays the real shape of welding tool designed in this work. As seen in Fig. 1, this two-fold pin was modelled from multistage pins for lap welding [25]. According to this model, the shape of the pin consisted of two parts. The shape of the first part that has contact with the top plate was cylindrical and the shape of the second part which has contact with the bottom plate was conical. The reason for selecting this design for the pin was for focusing on interface behaviour for hooking and thinning. It should be noted that during the welding process, the tool rotation direction was kept unchanged so that the left-handed threaded pin was rotating clockwise. Further, the tool shoulder was plunged into the top plate by a depth of around $0.15 \mathrm{~mm}$. Dwell time at the start point of welding was $20 \mathrm{~s}$. All FSLW conditions selected in this study are summarized and presented in Table 4 .

In order to identify the weld regions, macro etching was used to reveal the weld regions. Before etching, the electro spark wire-electrode cutting machine was used to cut off all samples from the welded plates of $60 \times 10 \times 5 \mathrm{~mm}^{3}$ in cross-sections perpendicular to the welding direction. The samples were used in the flat type after they were carefully prepared by applying standard metallographic techniques including wet-grinding using emery paper of $\mathrm{SiC}$ with different grit number sequences of $400,600,800$, and 1200 , fol-

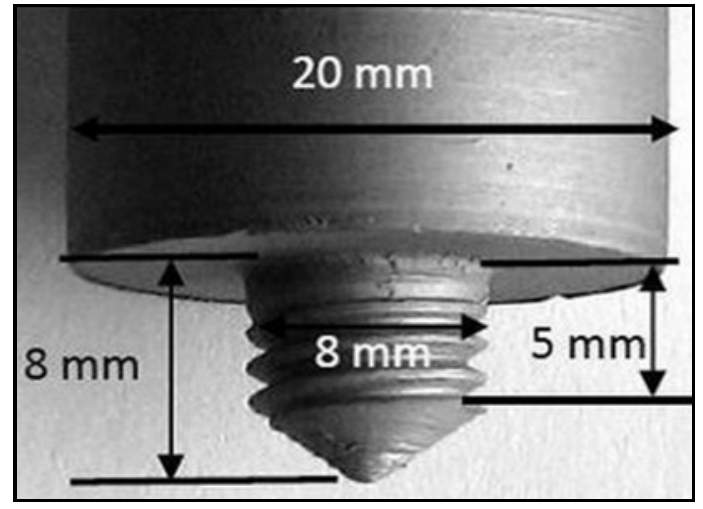

Fig. 1. Designed tool for friction stir lap welding.

lowed by polishing with $1 \mu \mathrm{m}$ diamond past, decreased by acetone, washed with double distilled water, and dried. In order to reveal the weld structure, according to ASTM standard E340 [26], samples were etched by immersion in a suitable etchant solution composed of $20 \mathrm{ml}\left(\mathrm{HNO}_{3}\right), 20 \mathrm{ml}(\mathrm{HCl}), 5 \mathrm{ml}(\mathrm{HF})$, and $60 \mathrm{ml}$ $\left(\mathrm{H}_{2} \mathrm{O}\right)$ for $1 \mathrm{~min}$, washed immediately with distilled water, dried in a cold stream of air. To identify the general microstructure of parent alloy and weld regions, based on ASTM standard E407 [27], the specimens were then etched with modified Keller's reagent composed of $5 \mathrm{ml}\left(\mathrm{HNO}_{3}\right), 3 \mathrm{ml}(\mathrm{HCl}), 2 \mathrm{ml}(\mathrm{HF})$, and $100 \mathrm{ml}\left(\mathrm{H}_{2} \mathrm{O}\right)$ for $2 \mathrm{~min}$, washed immediately with ethanol, and then dried in a stream of cold air. For revealing the parent alloy and weld regions grains morphology, etching was utilized. The etching was employed based on ASM standard [27] with some changes in the composition of etchant that obtained the best results. The etching solution was made with $45 \mathrm{ml}$ $\left(\mathrm{HNO}_{3}\right), 30 \mathrm{ml}(\mathrm{HCl}), 2.5 \mathrm{ml}(\mathrm{HF})$, and $42.5 \mathrm{ml}\left(\mathrm{H}_{2} \mathrm{O}\right)$. The etching time was considered as $1 \mathrm{~min}$. To achieve the necessary information about the welding speeds impact on the grain size, grain size was measured, and the image analysis of micrograph was performed. The grain size was obtained according to ASTM standard E112 [28] using linear intercept method.

In order to reveal the internal and external defects in the weldments, samples were inspected by visual inspection for identification of external defects and CT (Computed Tomography) Scan, X-Ray Imaging System (Hmxct-160xi (Xtek)) for revealing the internal defects. According to ASTM standard E384 [29], the 


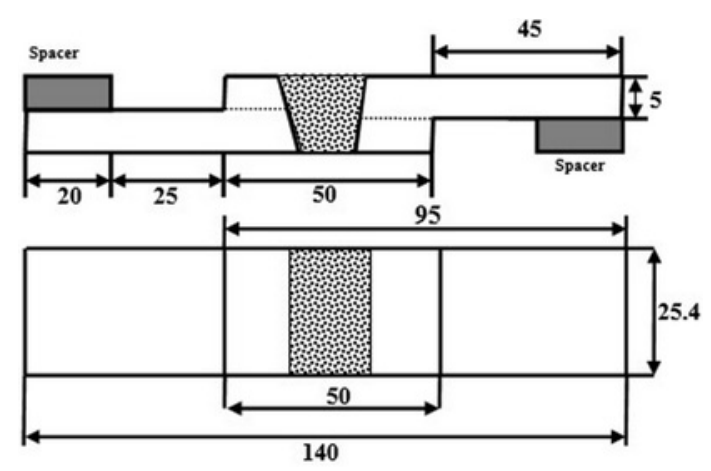

Fig. 2. Overlap shear test sample (all dimensions are in $\mathrm{mm}$ ) [30].

Vickers microhardness measurements of the FSLW region were carried out on cross-section perpendicular to weld direction of the mid-thickness of the top and bottom plate, using a square-base diamond pyramid indenter fixed on a microhardness tester at a load of $100 \mathrm{~g}$ every $2 \mathrm{~mm}$ by a dwell time of $10 \mathrm{~s}$. Due to no test standards for friction stir welded lap joints, ASTM: D3164 [30] providing a test method for strength properties of adhesively bonded joints was chosen as the reference test standard for lap shear test. Dimensions of the samples used for lap shear testing which are longer than the dimensions used by Cederqvist and Reynolds [8], are shown in Fig. 2. At room temperature, lap shear tests were conducted at a strain rate of $2.0 \mathrm{~mm} \mathrm{~min}{ }^{-1}$ by using a $100 \mathrm{kN}$ mechanical testing machine. For each tensile shear testing specimen, fracture locations were recorded. In order to identify effects of welding speeds on fracture properties of lap joints, the fracture locations of lap shear tensile test specimens were recorded. The analysis of the cross section of fracture was performed. Microstructural examination of AA6061-T6 welded lap joints after welding was analysed by optical microscopy (OM), scanning electron microscopy (SEM), and energy dispersive spectroscopy (EDS).

\section{Results and discussion}

\subsection{Macroscopic examination}

Hooking and thinning are the kinds of inherent feature appearing in FSL welded joints. They are distinguished as a crack-like that distorted from the original laying surfaces on the both advancing side (AS) and retreating side (RS). The hooking, thinning, and plate geometries on these two sides display heterogeneity as shown in Fig. 3.

According to this figure, some important observations can be made. First, the hooking and thinning features change with the welding process conditions. In this way, by reducing welding speed (Fig. 3), the hooking and thinning defects on both sides can extend downward towards the weld nugget zone (WNZ) indicating that the material in the TMAZ and in WNZ near the TMAZ/WNZ interface may experience some downward movement. Second, the hooking and thinning defects are visible only in the TMAZ region, which (here) only contributed to the region surrounding the weld nugget. It should be considered that severe plastic deformation is prepared by the passage of the tool within the weld region, which results in strain and heat generation. In this respect, the TMAZ region experiences minimum plastic strain and heat than
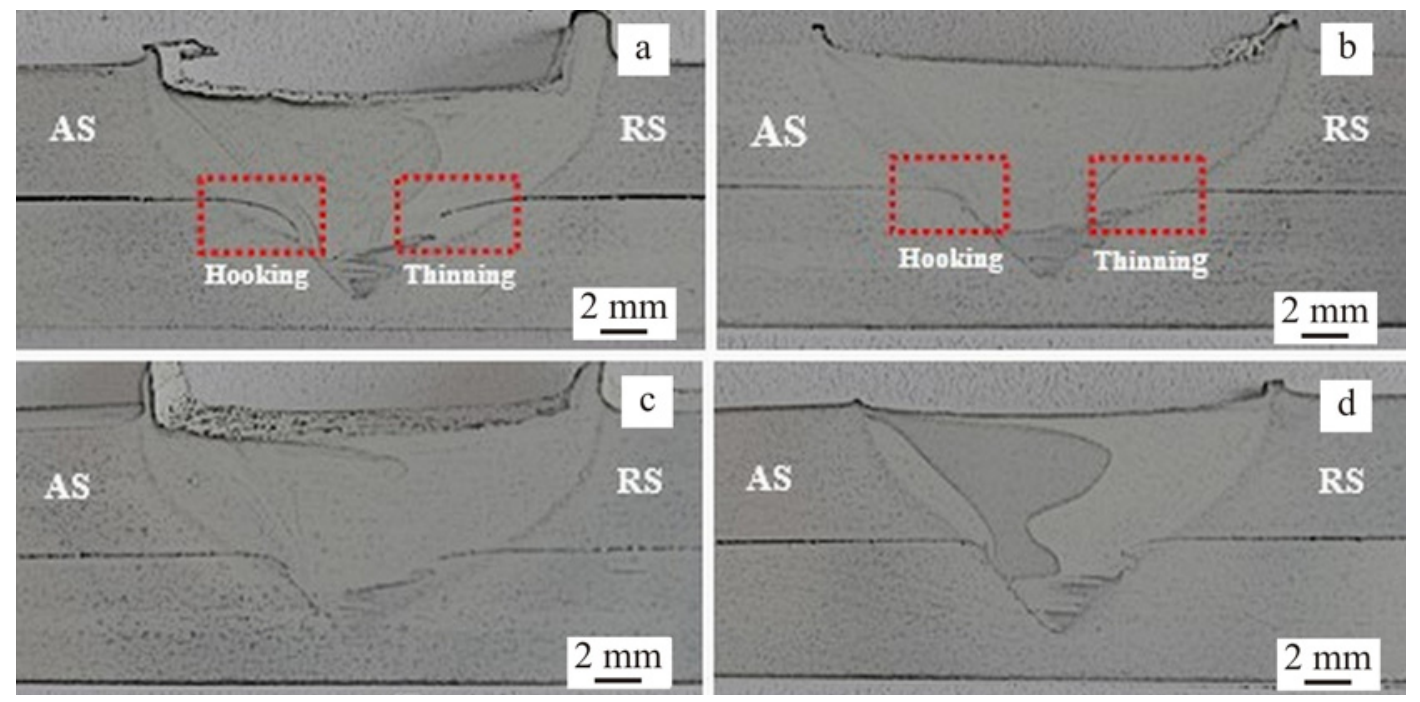

Fig. 3. Cross-section of macrostructures of welded lap joints at constant rotation speed $(\omega)$ of 1000 rpm, welding speed: (a) $20 \mathrm{~mm} \mathrm{~min}^{-1}$; (b) $40 \mathrm{~mm} \mathrm{~min}^{-1}$; (c) $50 \mathrm{~mm} \mathrm{~min}^{-1}$; (d) $60 \mathrm{~mm} \mathrm{~min}^{-1}$. 


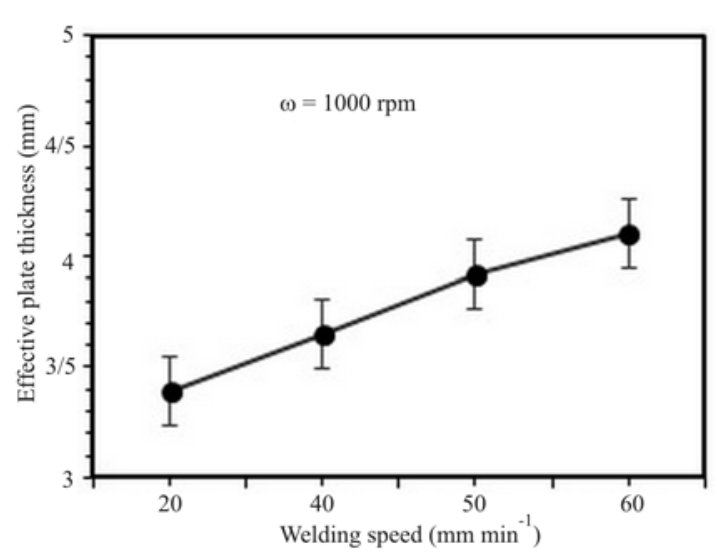

Fig. 4. Effect of welding speed on effective plate thickness (EPT).

the SZ. In spite of the TMAZ, any hooking and thinning may appear in the HAZ area since this zone only suffers from welding temperature impact. Third, the thinning on the retreating side has a downward direction and then extends to the stir zone by decreasing welding speed of 60 to $20 \mathrm{~mm} \mathrm{~min}^{-1}$. It means that when the welding speed increases, the progressing of thinning orientation was not arrested at the stir zone extremity. On the other hand, by increasing welding speed, the welding heat index (or heat input) during the FSLW was reduced, and low heat input (cold welding) condition leads to small hooking and thinning restricted to the WNZ/TMAZ interface. Fourth, it should be emphasized that although with decreasing welding speed or increasing rotation speed, the orientation of thinning on the retreating side is almost constant, but the shape of hooking on the advancing side can be gradually curved or can even have its direction suddenly altered. In this case, similar results were observed by other researchers $[9,11,31]$. Accordingly, it should be emphasized that the strength of weld joints will increase due to the restriction of hooking and thinning at the WNZ/TMAZ interface.

It should be emphasized that the effective plate thickness (EPT) can be applied to explain the hooking and thinning impact on the strength of welded lap joint quantitatively. In this case, some researchers published quantitative data about the EPT impact on the strength of welded lap joints [8, 22, 32]. The variation of the EPT of all welded samples in different welding speed and rotation speed is indicated in Fig. 4. According to data from this figure, the amount of EPT (effective plate thickness) which is related to variation in height and size of hooking and thinning was reduced because of an increase in height of hooking and thinning. As shown in Fig. 4, increasing welding speed from 20 to $60 \mathrm{~mm} \mathrm{~min}^{-1}$ causes EPT to rise $0.79 \mathrm{~mm}$. Yazdanian et al. [12], and Buffa et al. [20] have shown hooking and thinning are moving to the interface of two plates with an increase in welding speed. This means that the height of hooking and plate thinning (compared to interface line) decreased when the welding speed was increasing. As a result, an increase in the welding speed leads to increasing the height of hooking and plate thinning. Some published informations present a similar result in this case [11, 20, 22]. Furthermore, the amount of EPT, which is related to variation in height and size of hooking and thinning, was reduced because of an increase in height of hooking and thinning, as can be seen in Fig. 3 .

\subsection{Microscopic examination}

The optical images of microstructure observed from the various weld regions of all welded lap joints are pictured in Fig. 5. According to microstructure observations, some important findings are explained in the following.

First, the parent alloy is the part of the weldment that was not metallurgically affected by the welding process. It is located far from the weld. That means its microstructure remained unchanged throughout the entire welding process. Second, compared with the parent alloy, the HAZ shows some different microstructure. This means that the thermal cycle creates a clearly significant effect on the microstructure of welded alloy during the welding process. In this case, the HAZ has almost coarse grains similar to the parent alloy so that the size of grains is smaller than that of the parent alloy as observed in Fig. 5 .

The modification of structure in the HAZ can be attributed to the induced heat at this region and the cooling rates after FSLW. This result is reported by most researchers $[4,18,33-35]$. Third, it is evident that the original grain microstructure microscopically disappeared in the thermo-mechanically affected zone (TMAZ), and the transient microstructure between the WNZ and HAZ was achieved. In this case, although in all welding conditions, the transition between the WNZ and HAZ is easily obvious at the advancing sides, however, the transition area is not clear at the retreating sides, as shown in Fig. 5. The elongated grains (in the same direction) and dynamic recovered grain structure are considered as the TMAZ because the thermal and deformation conditions were not enough to create the recrystallized grain structure.

The size of grains within the weld region is normally changing with the alteration of the welding conditions. It demonstrates that the grain size increases with increasing the heat input within the weld region $[4,33,34]$. Figure 6 shows the variation of average grain size in the WNZ and HAZ with different welding parameters.

It was observed that with increasing welding speed, the grain size of the weld nugget zone decreased. It is clear that heat input and processing temperature 

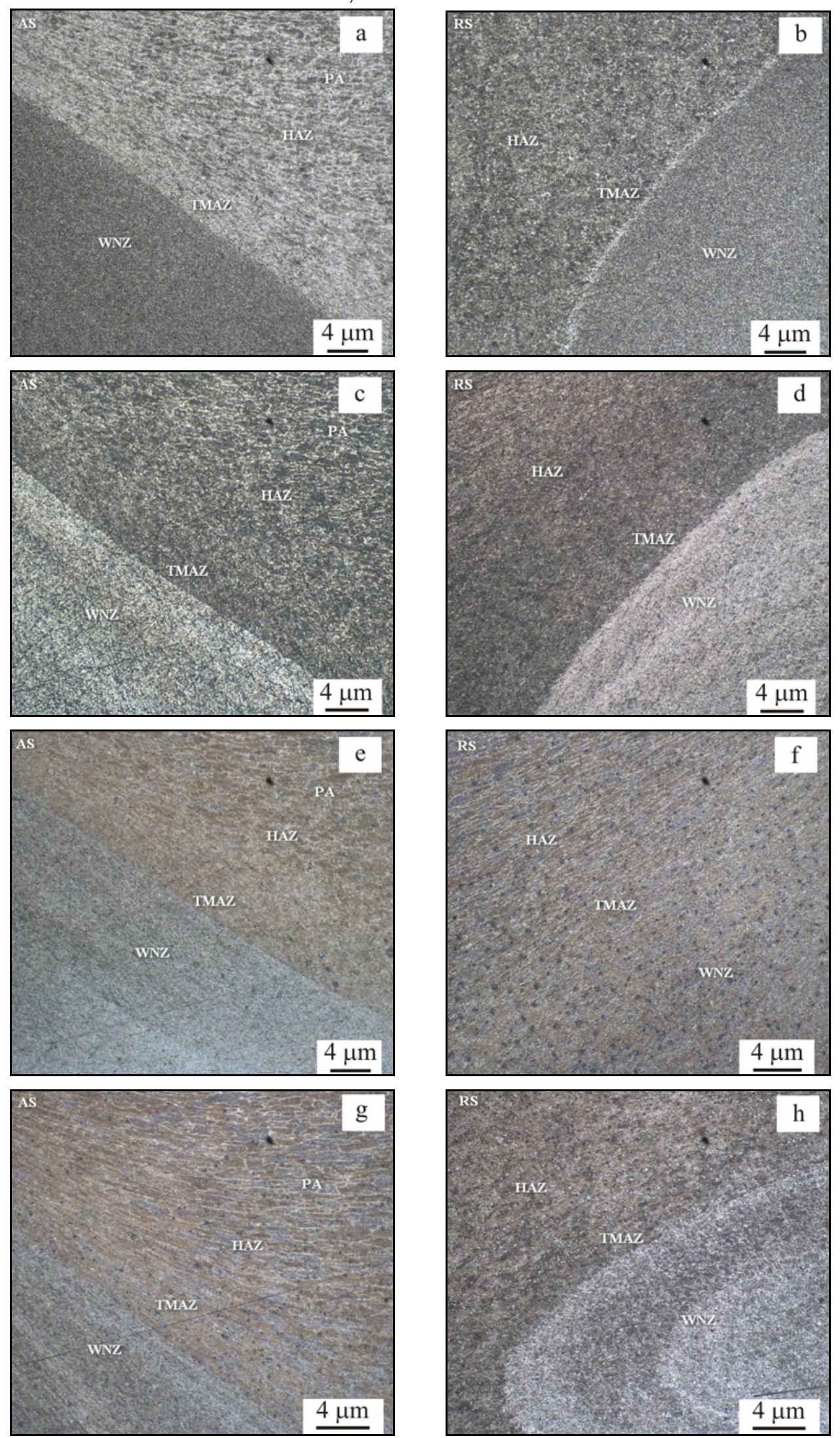

Fig. 5. Optical images of weld regions of microstructure at different welding conditions: (a), (b) $1000 \mathrm{rpm}-20 \mathrm{~mm} \mathrm{~min}^{-1}$; (c), (d) $1000 \mathrm{rpm}-40 \mathrm{~mm} \mathrm{~min}^{-1}$; (e), (f) $1000 \mathrm{rpm}-50 \mathrm{~mm} \mathrm{~min}^{-1}$; (g), (h) $1000 \mathrm{rpm}-60 \mathrm{~mm} \mathrm{~min}^{-1}$. 


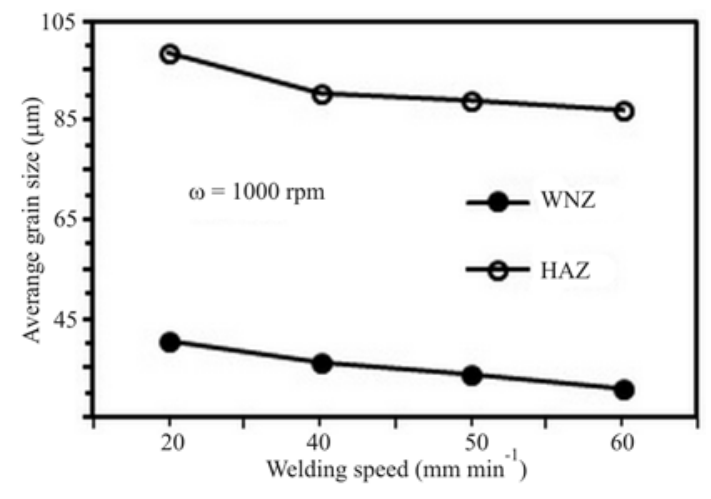

Fig. 6. Effect of welding speed at constant rotation speed on the average grain size of weld nugget zone (WNZ), and heat affected zone (HAZ).

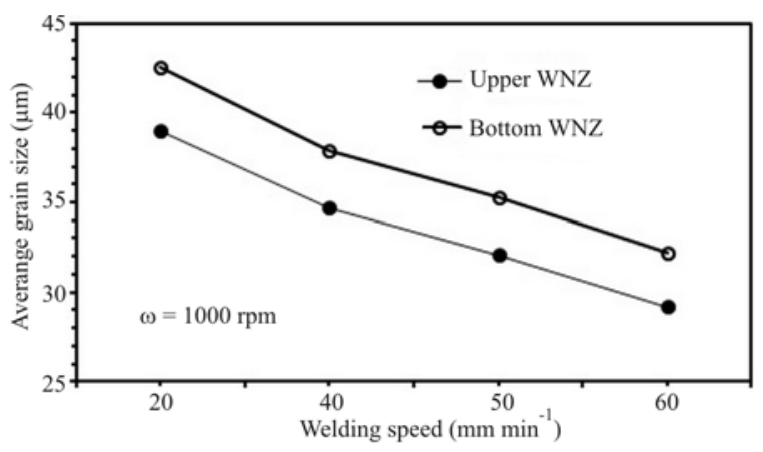

Fig. 7. Variation of average grain size in upper and lower weld nugget zone (WNZ) with the welding speed at constant rotation speed.

reduce with increasing welding speed. Conclusively, a lower temperature is in the weld nugget zone and a short time is available for grain growth after recrystallization resulting in smaller grain sizes in the WNZ of welded lap joints. As shown in Fig. 6, in the HAZ similar to the WNZ, the average grain size decreased with increasing welding speed. The average grain size in the HAZ decreased from 98.8 to $87.1 \mu \mathrm{m}$ with an increase in welding speed from 20 to $60 \mathrm{~mm} \mathrm{~min}^{-1}$.

The influence of different welding speeds on the variation of average grain size in upper and bottom weld nugget zone is shown in Fig. 7. It should be observed that due to higher pressure on the upper plate which resulted from shoulder friction in the upper plate, than on the bottom plate, the grain size in upper nugget was smaller than that in lower nugget in all welding conditions. It is clear that with increasing welding speed, grains at lower nugget always remain bigger than the grains in the upper one. This also has been reported by other authors [36].

\subsection{Mechanical properties}

Figure 8 depicts the welding speed impacts on lap

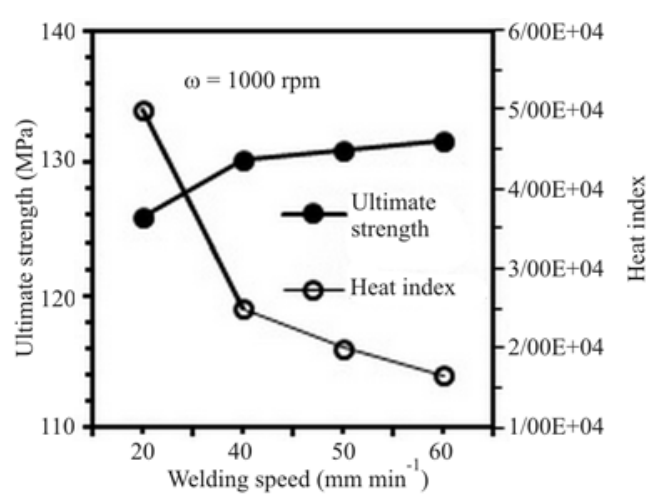

Fig. 8. Effect of welding speed on the variation of average ultimate shear strength and heat index at constant rotation speed.

shear strength and the heat index (HI) of lap shear specimens. It is observed that by reducing welding speed, lap shear strength decreases due to an increase of the failure load. In this case, it is worth mentioning that the failure load increases with the decrease of welding speed. It should be emphasized that the reduction of strength of welded lap joints may occur due to the altered and averaged microstructure in the zone as well as hooking and thinning or EPT during FSLW process. The EPT will be a change with hooking height and its size, which will be having a greater effect on welding strength compared to microstructure, which has been documented by previous researchers $[11,20,22,31]$. Cederqvist et al. [8] found that the higher lap shear strength is obtained at the larger EPT in aluminium alloy. Additionally, a larger EPT generates a larger load-carrying thickness, and joints with larger load carrying thickness can bear higher stress as reported by Dong et al. [37]. Thus, the failure load increases with the increase of the EPT. According to Fig. 8, it should be emphasized that by increasing welding speed, the value of welding heat input will be decreased. In this way, lower heat input increases the work hardening and viscosity in the poor flowability of the plastic material as reported in some references [4, 33, 37]. Accordingly, the hooking and thinning extend less distance downwards. Therefore, the tendency of EPT increases by increasing welding speed. Finally, when the EPT increases, the lap shear strength will be increased.

Figure 9 presents the joint efficiency of friction stir welded lap joints at various welding speeds and rotation speeds. It is important to note that the value of joint efficiency which is considered in this study is equal to the ratio of the ultimate tensile shear strength of lap joint to that of the ultimate tensile strength of parent alloy. According to this figure, the value of joint efficiency of the constant rotation speed of 1000 rpm was found to increase almost linearly from 40.6 to $42.5 \%$ with an increase in welding speed from 20 


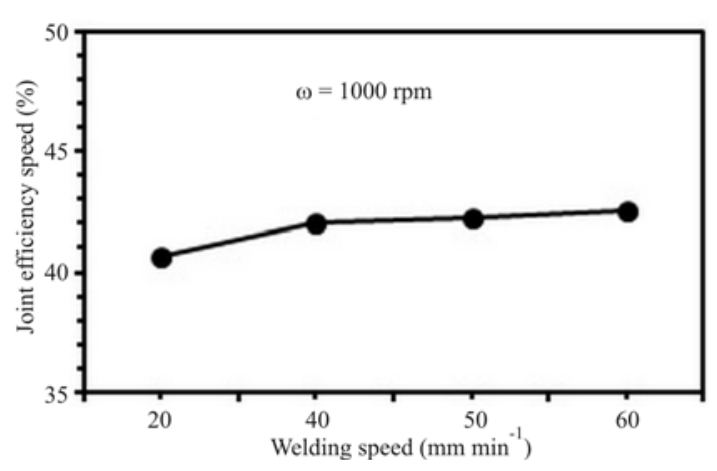

Fig. 9. Effect of welding speed on joint efficiency.

to $60 \mathrm{~mm} \mathrm{~min}^{-1}$. The obtained results from the value of joint efficiency at different welding speeds could be attributed to the effect of EPT and heat index (HI) on the lap shear strength of welded joints. It should be emphasized that by changing the EPT and HI at different welding conditions, the value of lap shear strength will be changed. Thus, by changing the value of lap shear strength, the value of joint efficiency also will be changed.

Figure 10 shows the variation of microhardness in the upper and lower plates with FSLW process parameters. The hardness decreased gradually from the BM through the HAZ, then increased slightly to the TMAZ, and finally decreased to the SZ while the lowest hardness was found in the HAZ on the advancing side of all welds. The figure clearly demonstrates that regardless of the process conditions, all welded lap joints had a softened region including the WNZ and HAZ as a comparison to a parent alloy.

In this respect, the WNZ and HAZ as softened regions are indirectly proving the findings of the strength of welded joints as opposed to the parent metal. It should be noted that the average microhardness of the weld nugget zone was determined to be lower (in the range of 59.85-65.95 HV) than the base metal (105 HV). Although higher hardness in the WNZ in contrast to the HAZ is governed by finer grains in the WNZ, the solution of precipitates by
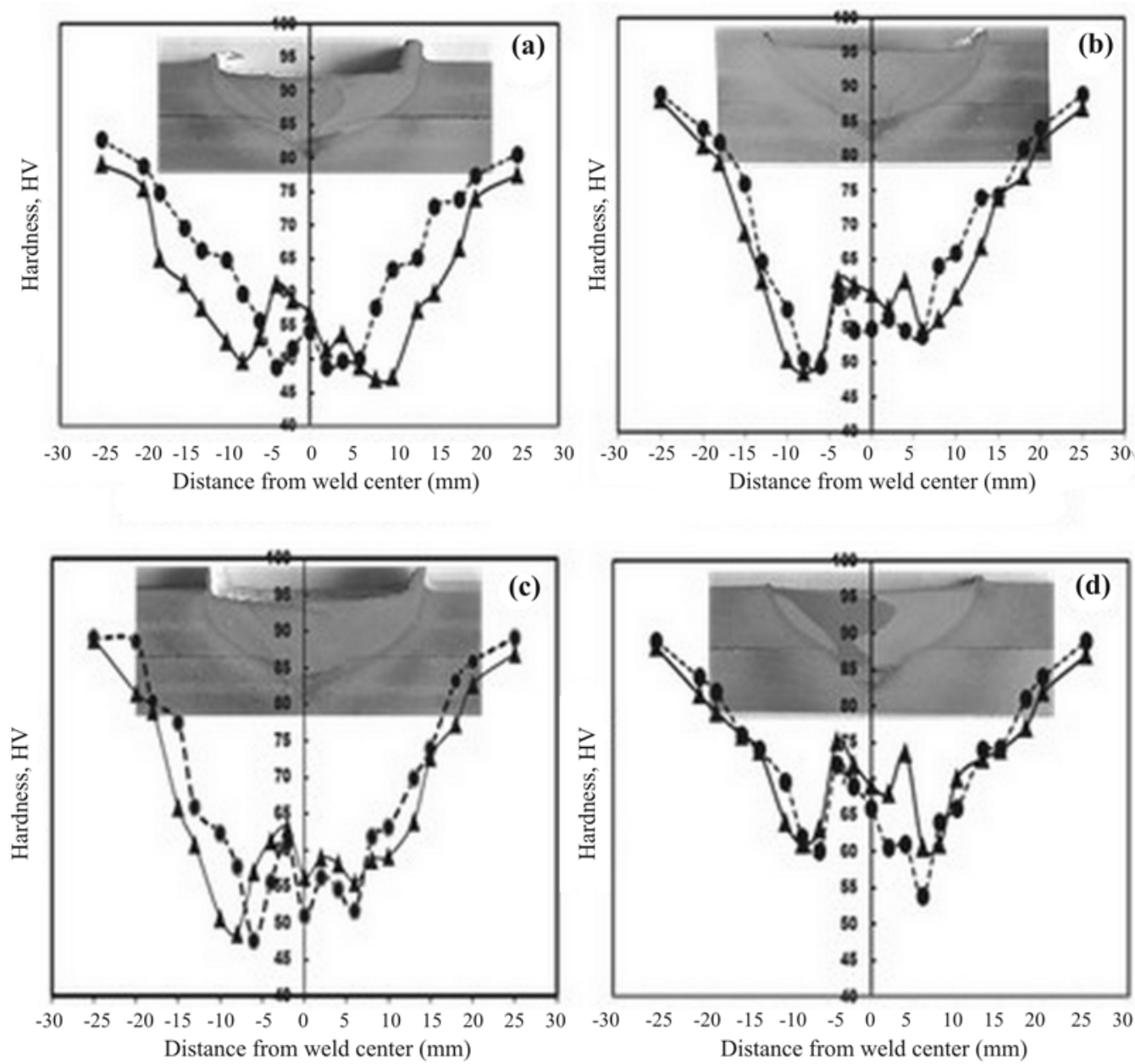

Fig. 10. Effect of welding speed (a) $20 \mathrm{~mm} \mathrm{~min}^{-1}$; (b) $40 \mathrm{~mm} \mathrm{~min}^{-1}$; (c) $50 \mathrm{~mm} \mathrm{~min}{ }^{-1}$; (d) $60 \mathrm{~mm} \mathrm{~min}^{-1}$ on hardness distribution along the mid-thickness of the upper and the bottom plate at a constant rotation speed (1000 rpm). 
Ta ble 5. Effect of welding speed on fracture properties of welded lap joints

\begin{tabular}{lcccc}
\hline & Sample 1 & Sample 2 & Sample 3 & Sample 4 \\
\hline Rotation speed $(\mathrm{rpm})$ & 1000 & 1000 & 1000 & 1000 \\
Welding speed $\left(\mathrm{mm} \mathrm{min}{ }^{-1}\right)$ & 20 & 40 & 50 & FM2 \\
\hline Fracture mode & FM1 & & \\
\hline
\end{tabular}

mechanical treatment and an increase in the welding heat input or heat index by decreasing in welding speed can also become other reasons for decreasing hardness in the WNZ and HAZ in comparison to the parent metal, for which a similar result has been reported by $\mathrm{Ma}$ [38]. It should be considered that the TMAZ on retreating side of the entire joint fabricated using different welding process parameters has a higher hardness in contrast to other weld regions, i.e., the WNZ and HAZ due to lesser grain coarsening as well as some work hardening impact left in the TMAZ. Although the microhardness of advancing side is lower than the retreating side, the microhardness curve is almost symmetric around the weld centreline. This can be attributed to the non-uniform field of plastic flow on both sides of the welded joints. In this way, the advancing side experiences higher plastic strain than the retreating side. It can be concluded that the temperature close to weld centre increased due to more deformation heat of the advancing side than that of the retreating side. Furthermore, lower microhardness on advancing side can be attributed to higher peak temperatures on advancing side which caused more grain coarsening than the retreating side as reported by Ericsson et al. [9]. The HAZ area at both advancing and retreating sides (almost $10 \mathrm{~mm}$ distance from weld centre) was determined to have a minimum hardness among the other regions of reported weld zone due to the grain coarsening. According to Fig. 10, it should be noted that by increasing the welding speed, the average hardness in the WNZ and HAZ increased whilst the difference between the top and bottom plate hardness in the WNZ decreased. However, for all welding parameters, the weld nugget zone has lower hardness compared to the parent metal. The parent metal has an average microhardness of about $105 \mathrm{HV}$. The average microhardness in the WNZ changes from 59 to $61 \%$ of the parent metal when welding speed rises up from 20 to $60 \mathrm{~mm} \mathrm{~min}^{-1}$. Conclusively, these obtained results of microhardness are in accordance with the re-

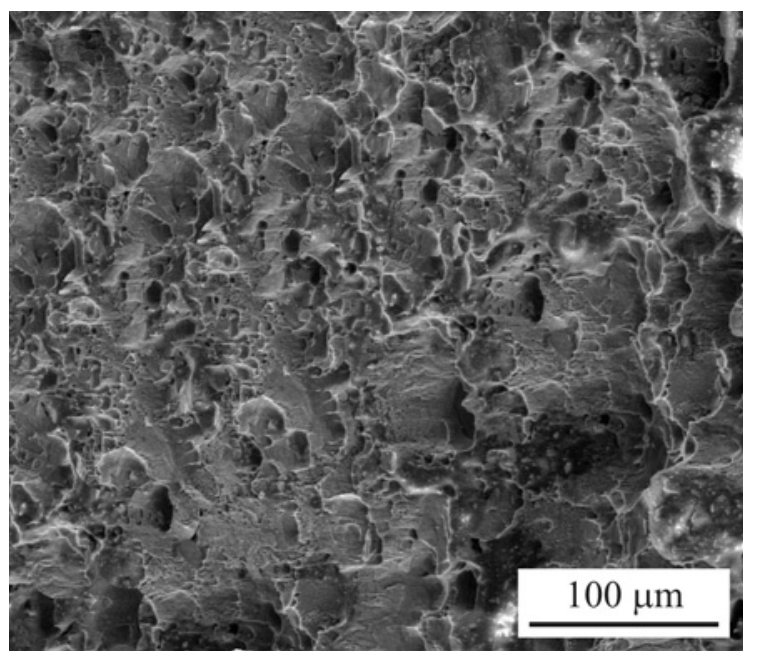

Fig. 11. The fracture surface of the overlap shear test samples by mode FM1.

sults of lap shear strength and the weld nugget grain size.

\subsection{Fracture behaviour}

Effects of welding speeds on fracture properties of welded lap joints of AA6061-T6 are illustrated in Table 5. As shown in Fig. 11, all fractured surfaces of lap joints which occurred by fracture mode FM1, which is denoted as fracture within the stir zone and on the retreating side of the bottom plate, invariably displayed dimples of varying sizes and shapes separated by tear ridges, which is an indication that most of the failures are naturally ductile. A similar phenomenon has been observed by Xu et al. [39]. On the contrary, in Fig. 12, fractured surfaces of welded joints which occurred by fracture mode FM2, which is denoted as plate separation along the hook throughout the stir zone, showed shallow dimples and sheared cleavage facets which introduced mixture fracture. A similar to this result has 


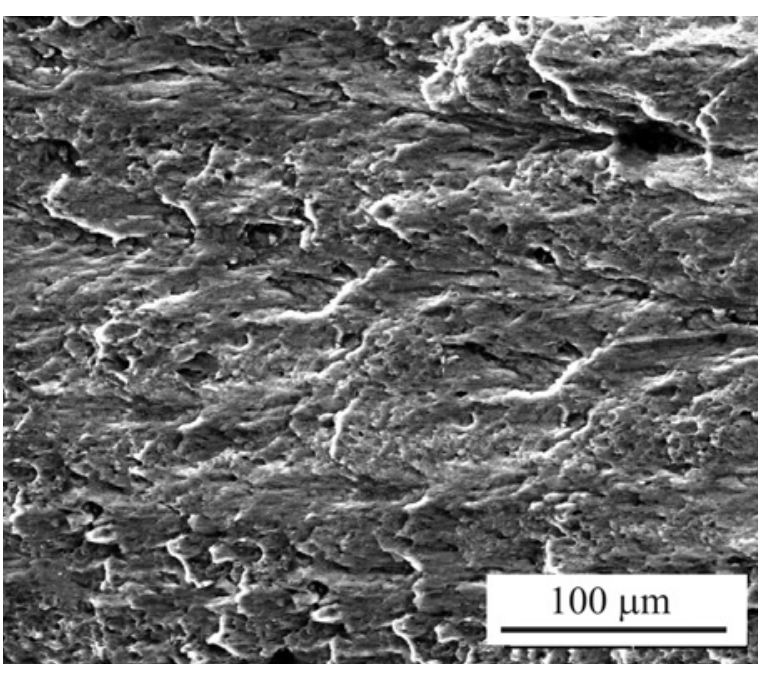

Fig 12. The fracture surface of the overlap shear test samples by mode FM2.

been reported by Zadpoor et al. [40]. The dimples relate to the onset of the fracture. After beginning of breaking, the welded samples experience overloading and the dimple is sheared (cleavage).

\section{Conclusions}

In the current investigation, the influence of welding speeds on weld quality of the FSLWed AA6061-T6 $\mathrm{Al}$ alloy was examined in terms of weld integrity, weld macro- and microstructure, hardness distribution, and tensile shear strength properties as well as effective plate thickness (EPT). The obtained results can be summarized as follows:

1. The hooking and thinning on both sides of welds are directed downward towards the bottom plate and then arrested at the WNZ/TMAZ interface with the increasing welding speed.

2. The average grain size in the WNZ rather than the HAZ area decreased with decreasing heat input. The average grain size on the upper plate in the WNZ was smaller than the WNZ on the bottom plate with increasing welding speeds.

3. The hardness of stir zone in all laps welded joints was slightly higher at a lower heat input (i.e., at a higher welding speed). The overall hardness across the TMAZ on the retreating side of all lap joints was higher than on the advancing side. The average microhardness of WNZ was higher than of HAZ with an increasing welding speed.

4. The tensile shear strength and joint efficiency increase with a decrease in the heat input (i.e., with an increase in welding speed).

5. The hooking and thinning defects were the main important factors that significantly reduced the ten- sile shear strength due to the reduced EPT. The EPT increased with an increase in welding speed.

6 . Two failure modes were observed when a friction stir lap weld was loaded in lap shear. The failure mode FM2 was the fracture mode within welded lap joints which had the highest tensile shear strength.

\section{Acknowledgements}

The authors wish to place sincere special thanks to Mr. Tajul Ariffin Md. Tajuddin, senior technician of Faculty of Engineering, Universiti Putra Malaysia (UPM), and Dr. Mohd Khairol Anuar Mohd Ariffin, Head of Department of Mechanical and Manufacturing Engineering, Faculty of Engineering, UPM, for their technical support.

\section{References}

[1] Thomas, W. M., Nicholas, E. D., Needham, J. C., Church, M. G., Templesmith, P., Dawes, C. J.: Friction Stir Welding. International Patent Application No. PCT/GB92102203 and GB Patent Application No. 9125.978.9. Cambridge, The Welding Institute TWI 1991.

[2] Lee, C. Y., Lee, W. B., Kim, J. W., Choi, D. H., Yeon, Y. M., Jung, S. B.: J. Mater. Sci., 43, 2008, p. 3296. doi:10.10007/s10853-008-2525-1

[3] Chen, H. B., Yan, K., Lin, T., Chen, S. B., Jiang, C. Y., Zhao, Y.: Mater. Sci. Eng. A, 433, 2006, p. 64. doi:10.1016/i.msea.2006.06.056

[4] Mishra, R. S., Ma, Z. Y.: Mater. Sci. Eng. R, 50, 2005, p. 1. doi:10.1016/j.mser.2005.07.001

[5] Dubourg, L., Merati, A., Jahazi, M.: Mater. Design, 31, 2010, p. 3324. doi:10.1016/i.matdes.2010.02.002

[6] Mahoney, M. W., Rhodes, C. G., Flintoff, J. G., Spurling, R. A., Bingel, W. H.: Metal. Mater. Trans. A, 29, 1998, p. 1955. doi:10.1007/s11661-998-0021-5

[7] Cantin, G. M. D., David, S. A., Thomas, W. M., Lara-Curzio, E., Babu, S. S.: Sci. Tech. Welding and Joining, 10, 2005, p. 268. doi:0.1179/174329305X39301

[8] Cederqvist, L., Reynolds, A. P.: Welding J. (Res. Supplement), 80, 2001, p. 281.

[9] Ericsson, M., Jin, L. Z., Sandstrom, R.: Int. J. Fatigue, 29, 2007, p. 57. doi:10.1016/i.ijfatigue.2006.02.052

[10] Ren, S. R., Ma, Z. Y., Chen, L. Q.: Scripta Mater., 56, 2007, p. 69. doi:10.1016/j.scriptamat.2006.08.054

[11] Cao, X., Jahazi, M.: Mater. Design, 32, 2011, p. 1. doi:10.1016/j.matdes.2010.06.048

[12] Yazdanian, S., Chen, Z. W.: IOP Conf. Series: Materials Sci. Eng., 4, 2009, p. 012021. doi:10.1088/1757-899X/4/1/012021

[13] Bitondo, C., Prisco, U., Squillace, A., Giorleo, G., Buonadonna, P., Dionoro, G., Campanile, G.: Int. J. Mater. Forming, 3, 2010, p. 1079. doi:10.10007/s12289-010-0958-y

[14] Aydin, H., Tutar, M., Durmus, A., Baryram, A., Sayaca, T.: Trans. Indian Inst. Met., 65, 2012, p. 21. doi:10.1007/s12666-011-0069-6

[15] Lim, S., Kim, S. A., Lee, C., Kim, S. U.: Metal. Mater. Trans. A, 35, 2004, p. 2829. doi:10.1007/s11661-004-0230-5 
[16] Khodir, S. A., Shibayanagi, T., Naka, M.: Mater. Trans., 47, 2006, p. 185. doi: $10.2320 /$ matertrans.47.185

[17] D'Urso, G., Giardini, C.: Int. J. Mater. Forming, 3, 2010, p. 1011. doi:10.10007/s12289-010-0941-7

[18] Sharma, C., Dwivedi, D. K., Kumar, P.: Mater. Design, 36,2012 , p. 379. doi:10.1016/j.matdes.2011.10.054

[19] Haydarzadeh, A., Khodaverdizaden, H., Mahmoudi, A., Nazari, E.: Mater. Design, 37, 2012, p. 166. doi:10.1016/i.matdes.2011.12.022

[20] Buffa, G., Campanile, G., Fratini, L., Prisco, A.: Mater. Sci. Eng. A, 519, 2009, p. 19. doi:10.1016/i.msea.2009.04.046

[21] Xu, X., Yang, X., Zhou, G., Tong, J.: Mater. Design, 35, 2012, p. 175. doi:10.1016/i.matdes.2011.09.064

[22] Yazdanian, S., Chen, Z. W., Littlefair, G.: J. Mater. Sci., 47, 2012, p. 1251. doi:10.10007/s10853-011-5747-6

[23] American National Standard AWS D17.3/D13.3M: Specification for Friction Stir Welding of Aluminum Alloys for Aerospace Applications. Miami, American Welding Society 2010.

[24] Metals Handbook: Heat Treating. Volume 4. Materials Park, ASM International 2003.

[25] Kallee, S. W., Nicholas, E. D., Thomas, W. M.: In: Proceedings of 3rd European Conference on Structures and Technologies - Challenges for Future Launchers. Paris, CNES 2001.

[26] ASTM Standard E340: Standard Test Method for Macroetching Metals and Alloys. West Conshohocken, ASTM International 1999. doi:10.1520/E0340-15

[27] ASTM Standard E407: Standard Test Method for Microetching Metals and Alloys. West Conshohocken, ASTM International 2007. doi:10.1520/E0407-07R15E01

[28] ASTM Standard E112: Standard Test Methods for Determining Average Grain Size. West Conshohocken, ASTM International 2013. doi:10.1520/E0112
[29] ASTM Standard E384: Standard Test Method for Knoop and Vickers Hardness of Materials. West Conshohocken, ASTM International 2011. doi: $10.1520 / \mathrm{E} 0384-16$

[30] ASTM Standard D3164: Standard Test Method for Strength Properties of Adhesively Bonded Plastic Lap-Shear Sandwich Joints in Shear by Tension Loading. West Conshohocken, ASTM International 2003. doi:10.1520/D3164-03R11

[31] Yang, Q., Li, X., Chen, K., Shi, Y. J.: Mater. Sci. Eng. A, 528, 2011, p. 2463. doi:10.1016/j.msea.2010.12.030

[32] Babu, S., Janaki Ram, G. D., Venkitakrishnan, P. V., Madhusudhan Reddy, G., Prasad Rao, K.: J. Mater. Sci. Tech., 28, 2012, p. 414. doi:10.1016/S1005-0302(12)60077-2

[33] Nandan, R., Debroy, T., Bhadeshia, H. K.: Prog. Mater. Sci., 53, 2008, p. 980. doi:10.1016/j.pmatsci.2008.05.001

[34] Liu, L., Nakayama, H., Fukumoto, S. J., Yamamoto, A., Tsubakino, H.: Mater. Trans., 45, 2004, p. 288.

[35] Ma, Z. Y.: Metal. Mater. Trans. A, 39, 2008, p. 642. doi:10.1007/s11661-007-9459-0

[36] Rajakumar, S., Muralidharan, C., Balasubramanian, V.: Int. J. Adv. Manu. Tech., 57, 2011, p. 151. doi:10.1016.S1003-6326(09)60387-3

[37] Rajakumar, S., Muralidharan, C., Balasubramanian, V.: Mater. Design, 32, 2011, p. 2878. doi:10.1016/j.matdes.2010.12.025

[38] Rai, R., De, A., Bhadeshia, H. K. D. H., DebRoy, T.: Sci. Tech. Welding and Joining, 16, 2011, p. 325. doi:10.1179/1362171811Y.0000000023

[39] Xu, W., Liu, J., Luan, G., Dong, C.: Mater. Design, 30, 2009, p. 1886. doi:10.1016/j.matdes.2008.09.021

[40] Zadpoor, A. A., Sinke, J., Benedictus, R.: Int. J. Mater. Forming, 2, 2009, p. 319. doi:10.10007/s12289-008-0144-7 